\title{
Inter-organisational Relationships in the Worldwide Popular Recorded Music Industry
}

\author{
Jonathan Gander and Alison Rieple
}

This paper analyses the worldwide popular recorded music industry and examines how product, firm and industry features result in key resources coagulating around the two firm types; the major and independent. We argue that these firm specific resources are complementary and participating firms would benefit from their union. However though complementary, they are inimical and close association risks damaging their value. Collaboration between the two firm types that hold these resources therefore needs to be designed not along traditional concerns of protection from opportunism, or the requirement to control key resources. Instead competitive advantage may be gained by designing and managing structural relationships that protect each partner's resource set from the hostile elements of the others; a contamination rather than an appropriation focus.

\section{Introduction}

\section{T} his paper examines boundary decisions taken by firms operating in the popular recorded music industry, and focuses on what can be regarded as one of the key drivers of the industry and source of competitive advantage; the identification and management of musical talent (Belinfante \& Johnson, 1982). An identification and discussion of product characteristics, market idiosyncrasies, and firm typologies results in the paper's overall proposition; that the resources and capabilities required to identify, attract and manage emerging talent cannot operate within the same business unit boundaries as those resources and capabilities required to effectively distribute and market the resulting product. The set of strategic resources and capabilities required to build sustainable competitive advantage therefore cannot co-exist within the boundaries of one firm. The resulting interorganisational structures can thus be seen not just as a means of accessing valuable and complementary resources and capabilities of another firm but also to shield the associating firms from exposure to inimical practices and culture of their partner. We therefore conclude that in the popular recorded music industry it is not just issues stemming from the cost of opportunistic partner behaviour, or social congruity that inform inter-firm structural decisions, but contamination concerns as well.

The music industry is dominated by a group of global firms commonly referred to as the 'majors'. These are the largest (by number of artists and soundcarrier market share) record companies in the world. The group currently consists of, Universal Music Group, (formed from a 1998 merger of MCA/Universal and PolyGram, previously majors in their own right), Sony Music Entertainment (SME); Bertelsmann Music Group Entertainment (BMGE); Warner Music Group (WMG) and EMI. These companies have a global market share of around $80 \%$. The remaining share is taken up by a large number of smaller, relatively short-lived and highly specialised companies known as the 'independents'. Music Business International (1999), producer of the industry's year book, defines independents as 'companies who derive most or all of their profits via the direct exploitation of music copyrights ... whose shares are at least $50 \%$ owned separately from the multinational music majors and who were not originally bankrolled by any of the majors.' Such a definition groups together one or two-man outfits with large organisations (sometimes known as 'mini-majors') such as Zomba, which has a wide range of artists, estimated 
turnover of $\$ 575 \mathrm{~m}$ in 1998 and a global distribution network. Since the 1950s, when independent music labels started to take advantage of the majors' reluctance to carry rock and roll music (Gillett, 1996), the independents and the majors have had an inter-worked history.

Throughout this highly interconnected history the relationships between major and independent firms have encompassed a wide range of structural relationships from full ownership, to distribution and licensing contracts lasting a few years or covering a few albums. Some writers (Peterson \& Berger, 1975) have pointed to the frequent acquisition of independents by majors and the differing organisational cultures as evidence of hostile relationships between these two ideal-types, with each form going through cyclical periods of fortune and power at the expense of the other. However in recent years, industry commentators (Negus, 1992; Frith, 1990) have identified a more co-operative model, similar to the conceptualisation of co-opetition advanced by Brandenburger \& Nalebuff (1996). Lopes (1992) has found support for the hypothesis that the oligopolistic conditions in the music industry (Belinfante \& Johnson, 1982) have not produced the homogenisation of product assumed to accompany such control (Peterson \& Berger, 1975) the identified diversity and innovation being due to a more open system of co-operation with independent record companies.

We propose that this current and historical pattern of close inter-organisational relationships between majors and independents reflects the industry's market and product idiosyncrasies (Hagedoorn \& Sadowski, 1999) and the simultaneously complementary and inimical nature of the firms' differing resources and capabilities (Dyer \& Singh, 1998). We begin by identifying the industry, firm and product idiosyncrasies that underpin the logic of collaboration and then discuss how the attempt to unify runs the risk of reducing the value, and impairing the operation, of the creative resources involved.

\section{Industry and product features that encourage major/independent collaboration}

One characteristic of the music industry is the oversupply of potential product creators (Throsby, 1994; Kretschmer, Klimis \& Choi, 1999; Hirsch, 1972). The raw material for the creative product, artistic endeavour, is subject to relatively low creation barriers, e.g. a guitar, paper, and enjoys a degree of intrinsic utility. This results in a large amount of potential product relative to the number actually marketed. Music research has so far been largely written on the victors (those artists who become successful), so figures on number of potential artists are unavailable. However Finnegan (1989) estimated there were around 100 practising bands in a UK city of around 100,000, and Negus (1992) cites Cohen (1991) as finding a similar proportion for the city of Liverpool in 1991.

This oversupply contributes to another noticeable feature of firms involved in cultural environments, that of uncertainty 'at their input and output boundaries' (Hirsch, 1972:639). As definitions of cultural goods commonly refer to their 'aesthetic, rather than clearly utilitarian purpose' (Hirsch, 1972:639) the evaluation of both the producers (artists) and their product relies upon matching already imperfect information on the talent of an artist (Strobl \& Tucker, 2000) against abstract and fluid criteria (Hutter, 1996). It is worth mentioning briefly at this point that, unlike 'pop' genres, the classical music market enjoys a relatively more stable predictive framework. Classical music recordings can be measured against more definable criteria, such as conductor or orchestra skill and reputation, popularity of the composer, and sound recording quality. Expert judgement on the quality of a recording is shared to a large degree by its market. However, classical music comprises a relatively small proportion of recorded music sales (currently about 5\% in Europe and the USA).

The oversupply of potential acts and uncertainty over their quality makes predicting which act are likely to 'take off' a task of extreme uncertainty. Perhaps the most notable effect of these factors is that it makes the ability to identify and capture (i.e. sign) tomorrow's mainstream act an industry success factor that cannot easily be substituted by a heavily funded large-net strategy. The challenge is summed up by one industry executive as 'What's weird today could be mainstream tomorrow' (Independent, 27th October 1991). Musical styles such as rock ' $n$ ' roll, punk, rap, and grunge have all had their origins in the rejection of the prevailing mainstream music. While large multinationals by virtue of their size, culture and reputation are to some extent distanced from grassroot musical developments, there are some indications that independents are better equipped to spot the next trend. These smaller record labels have greater artistic flexibility, closer ties to the non-mainstream music scene, and through their social similarities with the artists can inspire the trust (Zucker, 1986) that improves 
their ability to 'win' the signature of 'up and coming' artist(s). Although we are not aware of any published research which correlates the type of firm and the successful identification of new musical styles and artists, casual empiricism can comfortably identify examples of independent-discovered artists that have enjoyed notable success; Elvis Presley (Sun Records) Nirvana (Sub Pop Records), Oasis (Creation Records) and Britney Spears (Jive Records).

If one accepts that the identification of new talent is a 'critical key to success in the recorded music industry' (Belinfante \& Johnson, 1982:12) it is clear that the majors are critically dependent upon the independents.

Another defining characteristic of the popular music industry, the nature of consumer demand, provides the independent with a rationale for collaboration with a major. Demand patterns in the music industry, driven by dynamic consumer tastes for product with aesthetic rather than functional value, are highly variable and difficult to predict. This uncertainty of demand inherent in such cultural product (Caves, 2000) is exacerbated by the herding behaviour of individual consumers (Kirman, 1993) that results in a high concentration of sales among relatively few artists (Cox, Felton \& Chung, 1995).

Referred to as the 'superstar phenomenon' (Rosen, 1981; Hamlen, 1991) attempts have been made to explain how small differences in talent produce massive differentials in earnings, or even how no difference in talent (Adler, 1985) can produce high concentrations. The phenomenon of self-enforcing feedback loops (Arthur, 1996), decreased consumption costs (Adler, 1985), 'social contagion' (Kretschmer et al., 1999), or as Becker (1991:1110) puts it, buyer behaviour, 'depends positively on the aggregate quantity demanded of the good'. All refer to the utility derived from purchasing products that have been purchased by others, a feature of many cultural markets, but particularly visible in popular music. The dynamic thus experienced by a few artists is one of increasing returns. Although it does not result in the lock-ins which create monopolies as in Arthur's technology-based model or hypercompetition (D'Aveni, 1995), presumably because of the ephemerality of the music product, nevertheless there are large sales differentials between products that catch the wind and those that do not (Ormerod, 1998).

Due to this demand phenomenon, establishing initial interest and early sales to achieve the required momentum is key
(Strobl \& Tucker, 2000). Firms can accordingly devote substantial resources to the promotion of new product, which, while increasing the chances of catching the sales wind, exposes them to risk. Strauss Zelnick, ex-President/CEO of BMGE, has described how his company could spend around $\$ 1 \mathrm{~m}$ on a new act, yet of the 60,000 new records released annually by the record industry only $1 \%$ sell more than one million, the industry yardstick for success. The ratio for mere profitability is higher, though still daunting. Denisoff (1986) and Burke (1996) have both estimated that only one in ten albums would deliver positive net results for their labels.

For those products that enjoy the above snowballing effect, the low marginal costs of production produce very favourable revenue/ sales quantity relationships. In 1997, for example, the Financial Times estimated that PolyGram's per album profit would increase from $\$ 2$ for sales of 3 million units to $\$ 5$ for sales of 10 million. Maximising sales requires the physical distribution of what is a low unit value item, across disparate markets and numerous sales outlets. Such an exercise requires well developed logistical assets and competencies and enjoys significant economies of scale.

The above analysis suggests that a competitive music firm needs to have marketing competences and bargaining power to establish market awareness, sufficient financial resources to absorb inevitable product failures and to fund promotional campaigns, and a large output to allow it to benefit from available scale economies in distribution and manufacturing. The major's superior economic power therefore appears to complement the independent's knowledge based product development resources.

\section{The inimicality of complementary resources}

We argue that these product, firm and market-based idiosyncrasies demonstrate that both firm types (major and independent) enjoy a degree of resource complementariness (Chung, Singh \& Lee, 2000) and would thus benefit from the co-ordination of their particular assets and competencies. The paradox in the music industry is that while value can indeed be generated by the combination of resources, it is the maintenance of the boundaries between the firm types across which the respective resources and capabilities are exchanged that ensure their optimisation. We go on to discuss the reasons for such a paradox. 


\section{Discussion}

One source for the proposed inimicality is linked to the key strategic resource of an independent firm; its credibility. The firm and its key individuals' reputation among the various music and social scenes is crucial if the required trust is to be generated to encourage the artist(s) to place their early development in their hands (Hesmondhalgh, 1998). Close ties with a major can damage this asset and thus reduce the ability of the independent to attract the next star act. The music industry's highly networked social structure acting as an efficient conduit for such information (Burt, 1992).

The external impact of inter-organisational relations between majors and independents is matched by the possibility of negative internal consequences. The high levels of causal ambiguity over successful product creation, added to the distance between senior management and emerging music trends, restricts the ability of the major's hierarchically decision making structure to make effective interventions in the operation of the independent. In this respect the independents resemble the 'craft' organisation introduced by Stinchcombe (1959) and later defined by Powell as being where 'each product is relatively unique, search procedures are non-routine, and the work process depends to a considerable degree on intuition and experimentation' (Powell, 1987:68). The 'craft bureaucracy' framework requires a different management structure and environment to that typically adopted by large firms, which are characterised by centralised planning, hierarchies of decision-making, and clearly defined roles and tasks. The conventional monitoring and supervision systems designed to manage and control such explicit processes will be of reduced effectiveness (Leifer \& Mills, 1996) when applied to the more ambiguous process of popular music production and management.

In addition to hampering the production process of the independent, Ghoshal and Moran (1996) propose that such attempts can, by signalling mistrust, create mistrust and increase the likelihood of uncollaborative behaviour (Dyer, 1997; Wicks, Berman \& Jones, 1999). The use of hierarchy to control assets and protect against opportunistic behaviour (Williamson, 1985; Das \& Teng, 1996) when applied to creative resources can therefore be seen as either offering limited effectiveness or, in the worst case scenario, counterproductive results. The possibility of such a negative cycle is higher where there already exists potential for mistrust, such as in the wide cultural distance separating the major and independent. A 'them and us' perspective is part of the discourse of independent managers such as Allan McGee, head of a successful independent Creation, who described staff at a major music company with whom his company had had an alliance, as 'nice people but not my people'.

Thus, we argue, the restricted power of fiat to control and protect the major from uncooperative behaviour by the independent, when added to the self-defeating potential of its use, suggests that structural relations between the two firm types be designed to limit the independent's exposure to the bureaucratic processes and administrative preferences (fiat) of the major.

The conclusion, that resources held by the two firm types while complementary have mutually hostile features, runs counter to a central strategic management axiom; that sustainable competitive advantage lies in a firm's control over resources which are valuable, rare, hard to trade and difficult to imitate (Barney, 1991; Grant, 1991; Teece, Pisano \& Shuen, 1997; Dussauge, Garrette \& Mitchell, 2000). The resources and capabilities required to identify, secure and develop new musical talent, due to their social complexity and causal ambiguity offer strategic advantage (King \& Zeithaml, 2001), yet they resist full control by the majors who themselves control what are arguably only threshold resources, such as capital, logistical infrastructure support and marketing skills.

The variant to this hold and protect imperative (Porter, 1986), the share and learn perspective (Cohen \& Levinthal, 1990; Barney, 1991; Mowery, Oxley \& Silverman, 1996; Lorenzoni \& Lipparini, 1999; Khanna, Gulati \& Nohria, 1998, Teece, 2000) is also of questionable appropriateness in the music industry. The same idiosyncrasies that would restrict and degrade the transfer of creative resources in the form of people or credibility also apply to their movement in the form of explicit knowledge. Such knowledge is culturally embedded and socially constructed (Powell, 1987; Szulanski, 1995) and thus is inextricably tied to particular individuals and particular cultural environments.

It follows that sustainable competitive advantage can only be obtained through the development of relational competencies that preserve the value of both the major's but especially the independent's knowledge assets, maintain the incentive levels necessary for the independents' entrepreneurial behaviour, and at the same time secure the benefits of the resulting product for both firms. The alliance perspective that emerges is one 
where value-creating activities and even competitive advantage are not just contained within firm boundaries, but also reside in the unique combination of the collaborating firms' assets (Chung, Singh \& Lee, 2000, Holm, Eriksson \& Johanson, 1999; McConnell \& Nantell, 1985; Anand \& Khana, 2000) and the way the collaborating firms manage the relationship (Gulati, Nohria \& Zaheer, 2000; Kale, Singh, \& Perlmutter, 2000).

Viewed from this perspective, decisions over firm boundaries in the music industry are not made relative to the level of perceived threat presented by collaborating with another firm (Williamson, 1975, 1991), neither from the possible appropriation of key resources (Coase, 1937). Nor are they drawn in order to acquire, through integration, the resources identified as necessary to pursue a particular strategy (Porter, 1986). Rather they are drawn according to the need to protect the competences and intangible assets of the collaborating firm from contamination by the organisational and cultural features of their partner. A potentially useful metaphor suggests itself here; that the boundaries between these firms be viewed as semi-permeable membranes that can regulate exchanges between partners. It appears critical in this case that governance decisions are made with regard to their anticipated impact on this notional 'membrane'.

Effective operation of what can be termed this 'composite quasi rent' strategy (Hill, 1990:500) requires the careful patrol by both firm types of their organisational boundaries to ensure that mutually hostile elements of their resources do not cross along with the planned exchanges. For the independents there must be competencies in protecting the wilful artist from the source of promotional and management resources (the major), without conveying the sense that they are 'selling out' or at risk of losing their independence of spirit and decision-making. For the major, care must be taken to ensure that monitoring and control mechanisms typically employed by the firm toward its operations are adjusted in regard to the independent, and that operational collaboration (distribution, marketing aid) does not damage the independent's credibility.

\section{Conclusion}

It has been proposed that the strategic resources and capabilities held by the majors and independents, whilst complementary, are a feature of the typology of each firm and resist transfer from one to the other. The resulting paradox challenges firms to manage their boundaries not according to their concern over the possible cost of opportunistic behaviour, in other words what a partner might take, rather over what a partner firm might receive through association. Competitive advantage in such a scenario lies in a firm's ability to protect its partner(s) from exposure to its inimical practices and hostile features whilst at the same time benefiting from the union of their respective resources.

\section{References}

Adler, M. (1984) Stardom and talent. The American Economic Review, 75, 1.

Anand, B. and Khana, T. (2000) Do firms learn to create value? The case of alliances. Strategic Management Journal, 21, 3

Arthur, W. (1996) Increasing returns and the new world of business. Harvard Business Review, 74, 4.

Barney, J. (1991) Firm resources and sustained competitive advantage. Journal of Management, $17,1$.

Becker, G. (1991) A note on the restaurant pricing and other examples of social influences on price. Journal of Political Economy, 99, 5.

Belinfante, A. and Johnson, R. (1982) Competition, pricing and concentration in the U.S. recorded music industry. Journal of Cultural Economics, 6, 1.

BMG Distribution highlights success. Billboard (1999) February 6th.

Brandenburger, A. and Nalebuff, B. (1996) Coopetition. Doubleday, New York.

Burt, R. (1992) The social structure of competition. In Nohria, N. and Eccles, R. (eds.) Networks and organisations: Structure, form, and action. Harvard University Press, Cambridge, MA pp. 57-91.

Caves, R. (2000) Creative Industries. Harvard University Press, Cambridge, MA.

Chung S, Singh, H. and Lee, K. (2000) Complementarity, status similarity and social capital as drivers of alliance formation. Strategic Management Journal, 21, 1.

Coase R. (1937) The nature of the firm. Reprinted in Williamson O. and Winter S. (eds.) (1993) The nature of the firm: origins, evolution and development. OUP, New York.

Cohen, S. (1991) Rock culture in Liverpool: popular music in the making. Clarendon, Oxford.

Cohen, W. and Levinthal, D. (1990) Absorptive capacity: A new perspective on learning and innovation. Administrative Science Quarterly, 35, 128-152.

Cox, R. Felton, J. and Chung, K. (1995) The concentration of commercial success in popular music: an analysis of the distribution of gold records. Journal of Cultural Economics, 19, 4.

D'Aveni, R. (1994) Hypercompetitive Rivalries; managing the dynamics of strategic manoeuvring, Free Press, New York.

Das, T. and Teng, B. (1996) Risk types and interfirm alliance structures. Journal of Management Studies, 33, 6. 
Denisoff, R. (1986) Tarnished Gold: The record Industry revisited. Transaction Books, New Brunswick.

Dussauge, P. Garrette, G. and Mitchell (2000) Learning from competing partners: outcomes and durations of scale and link alliances in Europe, North America and Asia. Strategic Management Journal, 21, 2, 99-126.

Dyer, J. (1997) Effective interfirm collaboration: How firms minimise transaction costs and maximise transaction value. Strategic Management Journal, 18, 7, 535-557.

Dyer, J. and Singh, H. (1998) The relational view: cooperative strategy and sources of interorganizational competitive advantage. Academy of Management Review, 23, 4, 660-679.

Financial Times (1992) Steve Lewis November 29th, London.

Financial Times (1997) Bankable pop stars June 6th, London.

Finnegan, R. (1989) The hidden musicians: Music making in an English town. CUP, Cambridge.

Frith, S. (1990) Facing the music: essays on pop, rock and culture. Mandarin, London,

Ghoshal, S. and Moran, P. (1996) Bad for Practice: A critique of the transaction cost theory. Academy of Management Review, 21, 1.

Gillett, C. (3rd Edition. 1996) The sound of the city: The rise of rock $\mathcal{E}$ roll. Souvenir Press, London.

Grant, R. (1991) The resource-based theory of competitive advantage: implications for strategy formulation. California Management Review, 33, 3.

Guardian (2000) End of the revolution: Alan McGee January 19th, p. 14, London.

Gulati, R. Nohria, N. and Zaheer, A. (2000) Strategic Networks Strategic Management Journal, $21,3$.

Hagedoorn, J. and Sadowski, B. (1999) The transition from strategic technology alliances to mergers and acquisitions: an exploratory study. Journal of Management Studies, 36, 1.

Hamlen, W. (1991) Superstardom in popular music: Empirical evidence. The Review of Economics and Statistics, 73, 4.

Hesmondhalgh, D. (1998) The British dance music industry: a case study of independent cultural production. British Journal of Sociology, 49, 2.

Holm, D., Eriksson, K. and Johanson, J. (1999) Creating value through mutual commitment to business network relationships. Strategic Management Journal, 20, 5.

Hill, C. (1990) Co-operation, opportunism, and the invisible hand: Implications for transaction cost Theory. Academy of Management Review, 15, 3.

Hirsch P. (1972) Processing fads and fashions: An organisation-set analysis of cultural industry systems. American Journal of Sociology, 77, 4.

Hutter, M. (1996) The impact of cultural economics on economic theory. Journal of Cultural Economics, 20.

Kale, P., Singh, H. and Perlmutter, H. (2000) Learning and protection of proprietary assets in strategic alliances: building relational capital. Strategic Management Journal, 21, 3.

Khanna, T., Gulati, R. and Nohria, N. (1998) The dynamics of learning alliances: competition, cooperation and relative scope. Strategic Management Journal, 19, 3.
King, A.W. and Zeithaml, C. (2001) Competences and firm performance: examining the causal ambiguity paradox. Strategic Management Journal, 22, 75-99.

Kirman, A. (1993) Ants rationality and recruitment Quarterly. Journal of Economics, 108, 1, 137-156.

Kretschmer, M., Klimis, G. and Choi, J. (1999) Increasing returns and social contagion in cultural industries. British Journal of Management, 10.

Leifer, R. and Mills, P. (1996) An Information processing approach for deciding upon control strategies and reducing control loss in emerging organisations. Journal of Management, 22, 1.

Lorenzoni, G. and Lipparini, A. (1999) The leveraging of inter-firm relationships as a distinctive organisational capability: a longitudinal study. Strategic Management Journal, 20, 4.

McConnell, J. and Nantell, T. (1985) Corporate combinations and common stock returns: the case of joint ventures. The Journal of Finance, XL, 2.

Mowery, D., Oxley, J. and Silverman, B. (1996) Strategic alliances and interim knowledge transfer. Strategic Management Journal, 17, Winter special issue.

Music Business International (1999) Special Report on Independents. December, p. 11.

Negus, K. (1992) Producing Pop: culture and conflict in the popular music industry. Edward Arnold, London.

Ormerod, P. (1998) Butterfly Economics. Faber and Faber, London.

Peterson, R. and Berger, D. (1975) Cycles of symbol production: the case of popular music. American Sociological Review, 40, 2, 158-173.

Porter, M (1986) Competition in Global industries. Free Press, Cambridge, MA.

Powell, W. (1987) Hybrid Organisational Arrangements: New Form or Transitional Development? California Management Review, 30, 1.

Rosen, S. (1981) The economics of superstars. American Economic Review, 71, 5.

Stinchcombe, A. (1959) Bureaucratic and craft administration of production: a comparative study. Administrative Science Quarterly, 4.

Strobl, E. and Tucker, C. (2000) The dynamics of chart success in the UK pre-recorded popular music industry. Journal of Cultural Economics, 24, 2, 113-134.

Szulanski, G. (1995) Unpacking stickiness: An empirical investigation of the barriers to best practice inside the firm. Academy of Management Journal Best Papers Proceedings.

Teece, D., Pisano, G. and Shuen, A. (1997) Dynamic Capabilities and Strategic Management. Strategic Management Journal, 18, 7, 509-533.

Teece, D. (2000) Strategies for managing Knowledge assets: the role of firm structure and industrial context. Long Range Planning, 33, 35-54.

Throsby, D. (1994) The production and consumption of the arts: A view of cultural economics. Journal of Economic Literature, 32, 1.

Wicks, A., Berman, S. and Jones, T. (1999) The Structure of optimal trust: Moral and strategic implications. Academy of Management Review. 24, 1.

Williamson, O. (1975) Markets and Hierarchies. Free Press, New York. 
Williamson, O. (1985) The Economic Institutions of Capitalism. Free Press, New York.

Williamson, O. (1991) Comparative Economic Organisation: The analysis of discrete structural alternatives. Administrative Science Quarterly, 36, 2, 269-296.

Zucker, L. (1986) Production of trust: Institutional sources of economic structure 1840-1920. Research in Organizational Behaviour, 8, 53-111.
Jonathan Gander is Senior Lecturer, Business School, University of East London, UK.

Alison Rieple is Professor of Strategic Management, University of Westminster, UK. 